\title{
ESCENAS
}

(ensayos)

\section{Ojos de Giotto}

FIGURAS REVISTA ACADÉMICA DE INVESTIGACIÓN

ISSN 2683-2917

Vol. 3, núm. 1, noviembre 2021-febrero 2022

https://doi.org/10.22201/fesa.figuras.2021.3.1

\section{Giotto's Eyes}

https://doi.org/10.22201/fesa.figuras.2021.3.1.174

\section{Pablo Maurette}

Florida State University

Canto décimo sexto del Infierno. Estamos en la tercera fosa del séptimo círculo, el confín del Alto Infierno. Los peregrinos llegan a un risco y se disponen a bajar a Malebolge, el abismo de los fraudulentos, donde el poeta pasará más tiempo que en ninguna otra parada durante su largo viaje de ultratumba. Mientras esperan que alguien o algo los transporte hacia abajo, Dante es convocado por tres almas florentinas que purgan pecados de violencia contra Dios, la naturaleza y las artes. Estos tres condenados, que reconocen en Dante a un coterráneo por el atuendo, son Guido Guerra, un condottiero güelfo que cambatió en
Benevento y en Montaperti, Tegghiaio Aldobrandi, el podestà de Arezzo y uno de los capitanes florentinos en Montaperti, y Jacopo Rusticucci, otro político güelfo de quien se sabe poco y nada (salvo que estaba casado con una mujer muy demandante). Luego de intercambiar saludos, compartir algunas breves noticias y lamentar el estado moral de la Florencia del año 1300, una ciudad dominada por el afán de riqueza fácil, Rusticucci le augura a Dante una vida de fama y le pide, visto que decir la verdad es algo que le resulta tan natural al poeta, que hable bien de ellos cuando vuelva al mundo de los vivos - cuando vuelva a riveder le belle stelle (Inf. XVI...). El augurio de Rusticucci es especialmente sugestivo porque anticipa el último verso del Infierno (... e quindi uscimmo a riveder le stelle), pero también los últimos versos del Purgatorio y Paraíso, que concluyen ambos con la palabra stelle. Sin embargo, como suele suceder en Dante, lo sugestivo de la escena adquiere verdadera trascendencia cuando 
tenemos en cuenta lo que sucede inmediatamente después. El rumor de un arroyo invita a una bella digresión bucólica sobre la geografía de Italia luego de la cual el poeta se quita ceremonialmente la soga con que se había atado la túnica emulando a los frailes menores. Hecho esto, entrega la soga a Virgilio que la arroja al vacío a fin de - en sus palabras - convocar a una novità, a un ser de ensueño. Ese ser es el monstruo Gerión cuya figura apabullante dominará la escena inicial del canto siguiente. La advertencia del poeta antes de la aparición de Gerión es el momento crucial del que hablo:

\section{Sempre a quel ver c'ha faccia di menzogna de' l'uom chiuder le labbra fin ch'el puote però che sanza colpa fa vergogna; ma qui tacer nol posso, e per le note di questa comedia, lettor, ti giuro s'elle non sien di lunga grazia vòte, ch'i' vidi per quell'aere grosso e scuro... ${ }^{1}$}

(Inf. XVI 124-130)

Traduce Ángel Chiclana: "El hombre debe, siempre que pueda, cerrar sus labios antes de decir una verdad que tenga visos de mentira porque se expone a avergonzarse sin tener culpa. Pero ahora no puedo callarme y te juro, oh lector, por los versos de esta comedia a la que deseo la mayor aceptación, que vi venir nadando por el aire denso y oscuro...". ${ }^{2}$

En realidad, eso que Dante ve venir nadando hacia arriba está volando, pero en la imaginación del poeta se figura como un marinero que sube a la superficie luego de bucear hasta desprender el ancla de una roca. La metáfora determina el verbo. La imaginación poética toma precedencia ante la percepción. La jugada

1 Alighieri, Commedia, Vol. I, Inferno, 503.

2 Alighieri, La divina comedia, Kindle. no es inusual en Dante mas adquiere especial importancia cuando la precede esa increíble advertencia al lector que acabamos de escuchar. Como han notado ya muchos comentadores, esa verdad con cara de mentira es, en primer lugar, La Divina Comedia, poema visionario, escatológico y profético, presentado como ficción poética - una forma de realidad (de verdadrevelación), a un tiempo literal, figurativa y alegórica. En segundo lugar, esta verdad con cara de mentira es lo opuesto del monstruo Gerión y de lo que los peregrinos infernales encontrarán en Malebolge: el fraude, es decir, la mentira con cara de verdad. ${ }^{3}$ El poeta reafirma su credibilidad frente al lector antes de descender al bajo fondo de la mentira.

Dante utiliza con relativa frecuencia el recurso de la invocación al lector para generar verosimilitud a través de la confidencia y la camaradería. De hecho, hay veinte invocaciones al lector en La Divina Comedia. ${ }^{4}$ Pero esta es única por dos motivos. En primer lugar, incluye un juramento. En segundo, el juramento involucra al poema mismo que es nombrado por primera y única vez con el título que se usa hasta el día de hoy: "Comedia". La ironía de comprometerse a decir la verdad invocando la ficción sería sarcasmo de no ser porque Dante está precisamente proponiendo su visión poética como contracara del fraude.

3 Chiavacci Leonardi rastrea el origen de esta idea en un tratado latino, el De quattuor virtutibus, que el Medioevo atribuyó a Séneca (Cf. Alighieri, Commedia, Vol. I, Infierno, 503). Esta obra, citada por Brunetto Latini y Albertano da Brescia, distingue cuatro tipos de sentencias, según anota Guido da Pisa, un contemporáneo de Dante, en sus comentarios a la Comedia: 1) las que son verdaderas y parecen verdaderas, 2) las que son falsas y parecen falsas, 3) las que son falsas y parecen verdaderas, 4) las que son verdaderas y parecen falsas. Ver Guido Da Pisa, Expositiones et Glose super Comediam Dantis, 306.

4 Ver Auerbach, "Dante's Addresses to the Reader", 268-278. 
En un ensayo de 1955, Lanfranco Caretti reflexiona sobre este pasaje - un pasaje, dicho sea de paso, que ha sido relativamente descuidado por los dantistas. Dice Caretti que la continuidad sin fracturas entre el realismo extremo (los tres personajes históricos florentinos, la descripción de la geografía italiana), el simbolismo misterioso (la cuerda arrojada al vacío) y la fantasía desencadenada (el multiforme monstruo volador) imprime en estos versos finales, pero también en todo el canto XVI, una "evidencia unívoca que contribuye a la ilusión inalterada de una constante veracidad testimonial". ${ }^{5}$ En un poema plagado de situaciones inverosímiles e imágenes fantásticas, Dante elige este momento, justo antes de descender al Bajo Infierno donde se purga el fraude, para ungirse como el heraldo de la verdad con cara de mentira, de la ficción reveladora; y lo hace mediante un juramento que garantiza evidencia.

Pero volvamos por un instante al risco. Dante anticipa la llegada inminente de esa "novedad" anunciada por Virgilio, cuando de pronto el canto termina (es un cliffhanger literal). El canto siguiente, el décimo séptimo, se abre con la aparición del monstruo, una criatura con cara de varón honesto, cuerpo de serpiente, cola de escorpión y extremidades hirsutas que hacen las veces de alas. Gerión se posa sobre la cornisa y mientras Virgilio negocia con él para que los transporte al octavo círculo Dante, siguiendo el consejo de su maestro, se acerca para observar a las almas de los condenados por usura (una de las formas más abyectas de violencia), que arden en un arenal en llamas. En este caso Dante no reconoce a nadie. Cada uno lleva colgada del cuello una bolsa de dinero que observa embelesado mientras deambula en pena. Uno de ellos, cuya bolsa tiene el emblema azul de una cerda preñada, increpa al curioso poeta. Se identifica padovano y saca la lengua como un buey. Es Reginaldo

5 Caretti, "Storia e poesía (Inferno xvI)", 31.

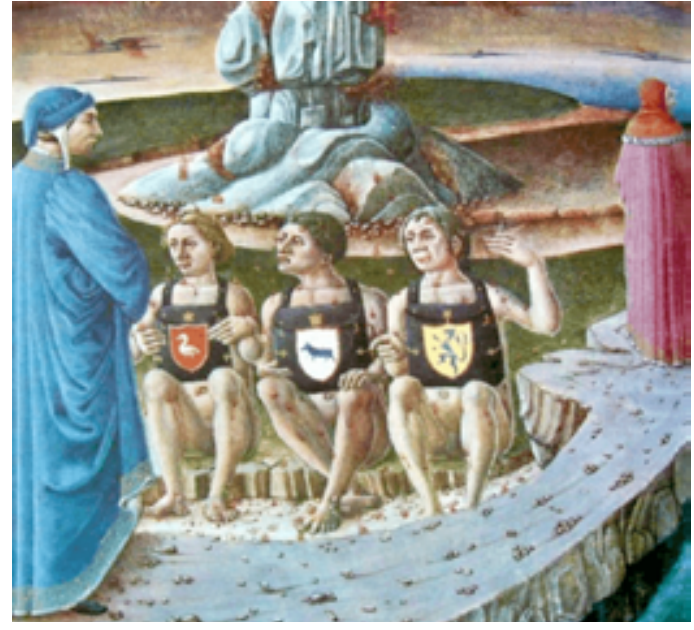

Dante frente a Reginaldo degli Scrovegni (en el centro y reconocible gracias al escudo familiar), canto XVII de la Divina Comedia. Fuente: progettostoriadellarte.it/

degli Scrovegni, un notorio usurero que vivió en la segunda mitad del siglo XiII. Sabemos que luego de su muerte, a fines del siglo XIII, la gente de Padua escandalizada por su codicia y enardecida por sus pecados amenazó con saquear su casa; y lo hubiera hecho de no haber sido por la promesa de su hijo, Enrico, que se comprometió a comprar el antiguo terreno donde estaba el teatro romano y construir un cenobio para los hermanos agustinianos y una iglesia dedicada a la Santísima Anunciación. La generosa donación tenía como objetivo purgar los pecados del impenitente Reginaldo que, según se cuenta, en su lecho de muerte, le dijo a Enrico: "El oro es poder, fuerza y salud". 6 Junto con la iglesia y el monasterio, Enrico mandó a construir una pequeña capilla y para decorarla contrató a Giotto, que ya gozaba de fama en toda Italia.

Giotto pintó la Capilla de los Scrovegni (también conocida como Capilla de la Arena) entre 1305 y 1306. No solo se trata de los frescos mejor conservados de su propia mano, sino que es uno de los complejos afrescados mejor conservados de la Edad Media. Hay tres series de historias, cada una en un nivel de las paredes.

6 Ver Gizzi, Giotto e Dante, 19. 
El extremo superior lo ocupan las escenas de la vida de los padres de la Virgen. En la parte central está la historia de la vida de María incluido el nacimiento de su hijo. Y, en la franja inferior, se cuenta la vida de Jesús. La capilla además incluye un deslumbrante Juicio Final, una serie de estatuas pintadas que representan vicios y virtudes (figuras en proto-perspectiva que simulan relieve), y diversas representaciones de ángeles y santos, animales y plantas.

Apenas uno entra a Scrovegni percibe la organicidad que hay entre los frescos y el espacio de la capilla. Para seguir la continuidad cronológica de las historias hay que moverse, caminar, cambiar de posición, darse vuelta, subir y bajar la mirada, aguzar los ojos, relajarlos. Es una experiencia de cuerpo entero. La sensación es de haber salido del mundo y haber entrado en un microcosmos antiguo y azul. El techo, un cielo estrellado, hace pensar en los finales estelares de las cánticas dantescas (también en el Mausoleo de Galla Placidia, en Ravenna), y transporta al espectador, habitante temporario de la capilla, a una anti- güedad mucho más lejana e indefinida de mausoleos bizantinos o de templos paganos, incluso de cavernas prehistóricas decoradas con coloridas figuras talismánicas de animales. En el muro opuesto al altar, un gigantesco juicio final con su Cristo y su Virgen entronada y el monstruoso Satanás de rigor rodeado de almas condenadas a los castigos más atroces, le recuerda al visitante el último capítulo en la épica de la escatología cristiana. Pero el impacto mayor es causado - esto uno lo entiende más tarde, después de haber salido pasados los míseros quince minutos de permanencia permitidos- por el efecto de totalidad englobante que tiene la capilla. El afán de exhaustividad de Giotto, el concepto de hacer del espacio entero una obra de arte anagógica y emotiva, se traduce en un efecto que trasciende la esfera de lo visual y se percibe en la carne misma.

¿Dónde aprendió Giotto a pintar así? Esas ovejas de mirada curiosa y lana mullida, esos perros inquietos, esos burros melancólicos, esos rostros desbordantes de afecciones, esos mantos minuciosamente

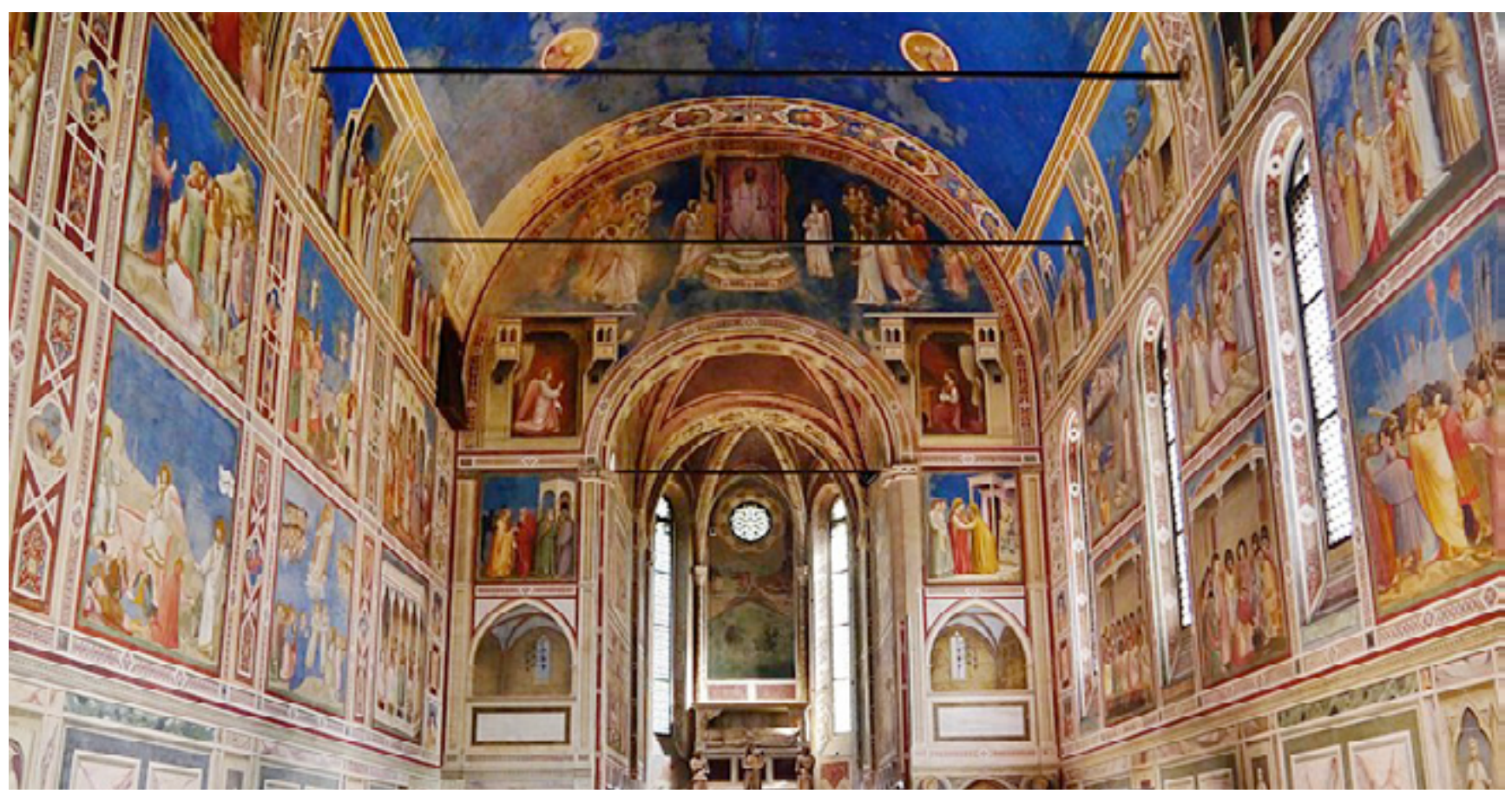

La nave de la Capilla de los Scrovegni en Padua, Italia, alberga ciclos de frescos de Giotto terminados sobre 1305.

Fotografía de Zairon, 2017. Fuente: Wikimedia Commons. 
ondulados y esos ojos. En especial esos ojos. El asombro ante el genio de Giotto es un lugar común entre los primeros que comentaron su importancia en la pintura y llega hasta Vasari. El denominador común de los elogios que llueven sobre el pintor toscano entre los siglos XIV y XVI tiene que ver con el carácter excepcional y transformador de su arte. Giovanni Boccaccio, acaso el primer intelectual que vio en Giotto a un renovador de la pintura, dice en el Decamerón (jornada sexta, cuento quinto) que el artista "... había resucitado aquel arte que había estado sepultado durante muchos siglos debajo de los errores de algunos que más se ocupaban en recrear la vista de los ignorantes que en complacer la inteligencia de los sabios, puede llamársele merecidamente una de las luces de la gloria florentina...". ${ }^{7}$ Filippo Villani, uno de los primeros historiadores florentinos, incluye a Giotto en la serie de biografías de grandes personalidades de Florencia que había comenzado su padre, y dice que el pintor "restituyó la antigua dignidad a la pintura". 8 Cennino Cennini, en su Libro del arte, un manual para jóvenes pintores escrito en los primeros años del siglo XV, opina que Giotto "tradujo el arte de pintar del griego al latín", 9 es decir que, gracias a él, la pintura italiana abandonó los usos y formas bizantinas y adoptó un estilo más fiel a la naturaleza. Unas décadas más tarde, en los Comentarios, Lorenzo Ghiberti, que identifica a Giotto con la Etruria debido a sus orígenes toscanos, estima que el artista condujo la pintura a "grandísima perfección" y habla de un resurgir del arte luego de más de 600 años de barbarie. ${ }^{10}$ Por último, ya en el siglo XVI, Giorgio Vasari lo considera el

7 Boccaccio, El Decamerón, 561.

8 Villani y Mazzuchelli, Le vite d'uomini illustri fiorentini, 47.

9 Cennini, Il libro dell'arte: A new English translation and Commentary with Italian Transcription, 20.

10 Ghiberti, I comentario, Biblioteca Nazionale Centrale di Firenze, II, 84-85. gran restaurador del disegno, uno que pintaba a partir de la naturaleza (di naturale), uno que "dio a luz a la pintura", y repite la historia (referida antes por Ghiberti y casi seguramente ficticia) de cómo lo descubrió Cimabue de casualidad, cuando era niño, en la montaña, dibujando una oveja sobre la superficie de una roca. ${ }^{11}$

La tradición posterior, -me salto los siglos XVII, XVIII y gran parte del XIX, periodo durante el cual el estilo giottesco es mayoritariamente considerado rudimentario - sigue la línea marcada por Vasari y considera que Giotto, aparte de ser el precursor de la perspectiva lineal, es pionero en promover y desarrollar el naturalismo. El artista toscano es visto como un pintor sensible a la particularidad de formas y de emociones, cuyo principal objetivo estético consiste en reproducir el mundo. Giotto es entendido en muchos casos como parte funcional, fundamental incluso, de la reforma estética y devocional promovida por el franciscanismo. ${ }^{12}$ La lectura es convincente no solo por el estrecho vínculo entre el pintor y dicha orden monástica, sino por las características más notables de su trazo. En los frescos de la Basílica Superior de Asís y en la capilla Bardi, en Santa Croce, las figuras de Giotto, insólitamente plásticas, humanas, táctiles, frágiles, anuncian una nueva forma de rezar y de imaginar la historia sacra. Una y otra vez, críticos y admiradores resaltan el efecto de presencia y de realidad que tiene la mano de Giotto. En una carta a Emile Bernard, Van Gogh cuenta sus impresiones frente a un Giotto, una tabla pintada a témpera: "Las expresiones de dolor y de éxtasis son humanas a tal punto

11 Vasari, Le vite de'più eccellenti pittori, scultori e architettori, 295-332.

12 Cole, Giotto and Florentine Painting 128o-1375, 17. Thode, Giotto, Künstler-Monographien 43. Auerbach, Il fattore personale nell'ascendente di San Francesco d'Assisi, 15-26. 
que no parece que estuviéramos en el siglo XIX, sino que pareciera como si estuviéramos ahí presentes tanto participa uno de la emoción". ${ }^{13}$ El Santo Stefano del Museo Horne, el San Antonio de la Colección Berenson, el San Francisco recibiendo los estigmas del Louvre y la Madonna di San Giorgio alla Costa, tienen un efecto similar en el espectador. Se imponen a la sensibilidad con inmediatez a la vez que generan el efecto de lo atemporal. Son presencias con peso, profundidad y espesor que parecen desconocer por completo los límites impuestos por la bidimensionalidad de la tabla o del muro. Su existencia está más allá de toda duda. Existen en sí y por sí. Así se imponen y así se nos presentan, como si no necesitaran de nosotros, pero sobre todo como si no necesitaran del artista, como si no fueran artificios. Las figuras de Giotto son evidentes en y por sí mismas, como es evidente una oveja pastando en el valle o el pastor que la guía por el valle y que, en un momento de ocio, la retrata con la punta de una rama quemada o con un guijarro sobre la superficie de una roca.

Pero hay otro Giotto. Un Giotto no naturalista, aunque sí realista. Este Giotto es un artista para quien la imitación fiel del mundo no es el principal objetivo, sino un mecanismo más en la creación de un universo propio que es imagen figurativa de una realidad ontológicamente superior a la que el artista accede de manera mística o intuitiva. Un bosquejo brillante de este Giotto nos es dado por Proust en el sexto volumen de la Recherche, Albertine disparue. Ésta es una impresión del narrador después de su visita a Scrovegni: “... los santos vuelan con un ímpetu tan celestial o tan pueril que parecen individuos de una especie que existió realmente y que apareció en la historia natural de los tiempos bíblicos y evangélicos..."14. Éste es un Giotto

13 Citado en De Benedictis, Giotto: Bibliografía Vol. II (1937-1970).

14 Proust, En busca del tiempo perdido 6. La fugitiva, 270. supernaturalista, cuyo poder evocativo es capaz de demostrarnos la existencia tangible de realidades inteligibles. Esta intuición proustiana encuentra un correlato más especulativo en el análisis de Roberto Salvini que a través de una lente hegeliana ve a Giotto como un artista cuya obra es la expresión de la "consciencia de una relación directa entre el espíritu del artista y las apariencias del mundo sensible, en el sentido de una transposición fantástica de una naturaleza que el espíritu pone como objetiva y real". ${ }^{15}$ Para Salvini, la visión totalizante de Giotto se impone sobre el interés en imitar las particularidades de la realidad sensible. Esta idea de la preponderancia de la totalidad de la obra ante el detalle mimético de la figura individual ya aparecía en la lectura que propuso Richard Offner en ocasión de la gran muestra giottesca de 1937, organizada en conmemoración de los seis siglos de la muerte del artista. Offner entiende que Giotto subyuga la forma individual al orden y equilibrio general, lo cual "implica un tratamiento no-naturalista de la figura". ${ }^{16}$ Coincide con él Hans Belting, que resalta el franciscanismo de Giotto y concluye que las imágenes giottescas, "a diferencia de lo que se cree comúnmente, no son un espejo del mundo exterior tanto como el escenario de un drama en el que los actores representan un vasto espectro de sentimientos y relaciones humanas...". ${ }^{17}$ Se trata, entonces, de un Giotto, llamémoslo plotiniano, cuyo modelo para retratar el mundo no es el mundo mismo sino la dimensión de las ideas, de las que las cosas son imágenes degradadas.

15 Salvini, Giotto: La cappella degli Scrovegni, 21.

16 Offner, "Giotto, Non-Giotto", en The Burlington Magazine for Connoisseurs, 260. Puede consultarse digitalmente en: https://www.jstor.org/stable/867802

17 Belting, "The New Role of Narrative in Public Painting of the Trecento: "Historia" and Allegory." 153. Puede consultarse digitalmente en: https://www.jstor. org/stable/42617840. 
Voy a proponer un tercer Giotto. Sin dejar de lado (aunque sería aconsejable) ${ }^{18}$ la convicción sobre la absoluta excepcionalidad de Giotto y el rol fundamental de su revolución estilística en la historia del arte, intentaré poner entre paréntesis nociones como las de realismo y naturalismo para entender la efectividad de su estilo pictórico desde otro lugar. El naturalismo de Giotto, convertido por Vasari en el elogio canónico del pintor, fue puesto en duda brutalmente por el gusto de los siglos XVIII y XIX, cuando algunos de sus frescos, considerados primitivos, fueron cubiertos con cal (los de la capilla Peruzzi en Santa Croce, por ejemplo). En una guía a los frescos de Scrovegni, publicada en 1854, John Ruskin expresa el gusto de la época cuando dice que los dibujos de Giotto son extremadamente defectuosos, pero agrega que el pintor obviamente no hace el mínimo esfuerzo por imitar la realidad, sino que su arte apela a la imaginación y es de corte simbólico. ${ }^{19}$

Es difícil no aceptar, al menos en parte, la apreciación de Ruskin. Las figuras de Giotto son anatómicamente inadecuadas (véanse, por ejemplo, los dedos de la mano izquierda de Santo Stefano o los pies del pastor en "El sacrificio de Joaquín"), sus paisajes oscilan entre lo arquetípico y lo onírico, e incluso su paradigmático poder de concentración de la acción dramática es

18 No cabe duda de que la idea de la irrupción de Giotto en la escena artística italiana como un acontecimiento ex nihilo es un sinsentido. Ya muchos han señalado los antecedentes directos del artista en la escultura gótica internacional, en los púlpitos de Nicola Pisano, en los mosaicos de Pietro Cavallini e incluso en la pintura romana antigua redescubierta durante el siglo XIII. Eso sin mencionar los crucifijos pintados de Giunta y de Cimabue y, desde luego, la literatura de la que se nutre Giotto, obras como las Meditaciones sobre la vida de Cristo y la Leyenda áurea, de Jacobo de Vorágine.

19 Ruskin, Giotto And His Works In Padua: Being An Explanatory Notice of the Series of Woodcuts Executed for the Arundel Society After the Frescoes in the Arena Chapel, 36-38. efectivo a costa de la verosimilitud. El conocimiento rudimentario de la anatomía humana en la era inmediatamente anterior a la así llamada revolución anatómica de los siglos XV y XVI es de hecho una ventaja para Giotto. La imitación meticulosa del cuerpo, de cada músculo en sus diferentes estados de tensión y relajamiento, puede resultar una tentación para el artista deseoso de exhibir virtuosismo (como sucederá en la segunda mitad del Cinquecento) y una distracción para el espectador. Respecto del supuesto realismo de Giotto, entendido como construcción de un universo visible a imagen y semejanza de uno invisible e inmutable, la duda radica precisamente en el interés innegable de Giotto por dar cuenta de la particularidad, de lo único e irrepetible del instante emotivo, del gesto, del exabrupto. En otras palabras, a Giotto le interesa demasiado la particularidad como para ser un realista y la retrata de manera demasiado afectada como para ser un naturalista. ¿Qué es entonces lo que da tanta efectividad a su arte? Este tercer Giotto que propongo es un intento de respuesta.

La efectividad es producto de una ilusión. La ilusión del espacio completo. Esta ilusión genera evidencia. Varios comentadores a lo largo del siglo xx señalaron la importancia del concepto de evidencia en la obra de Giotto. ${ }^{20}$ Max Imdahl, en una monografía sobre los

20 Brinckmann dice que Giotto renueva la pintura al conferir a los cuerpos "evidencia plástica y volumétrica". Brinckmann, "Dante und die blindende Kunst." Kunstchronik und Kunstmarkt, 897-903, https:// doi.org/10.11588/diglit.36987.71. Offner señala que la composición giottesca subyuga la forma individual a la totalidad orgánica produciendo una "evidencia predominante" (Offner, "Giotto, Non-Giotto-II.", 260, el artículo puede consultarse digitalmente en http:// www.jstor.org/stable/867891). Battisti, por su parte, identifica la excepcionalidad de Giotto con esta "evidencia" de sus imágenes, que ni los bizantinos ni los representantes del gótico internacional habían logrado (Battisti, "Giotto nel Trecento", en Rinascimento e Barocco, 69.). 
frescos de Scrovegni, resalta este concepto y argumenta que el efecto de evidencia (Evidenz) está dado por la independencia de cada imagen respecto de la historia de la que forma parte. Asimismo, el conjunto de cada escena se sostiene independientemente de la totalidad de la capilla. A la vez, es la obra completa la que da sentido a cada escena y a cada personaje individual. Esta dinámica fluida que se da entre las partes y los todos confiere concisión y una "altísima e inmediata evidencia" al complejo pictórico, concluye Imdahl. ${ }^{21}$ La noción de evidencia se puede aplicar a toda la obra de Giotto, y tal vez sea más destacable en obras que han sido removidas de su locación original, como la Madonna de Ognissanti (hoy en los Uffizi) o el Santo Stefano del Museo Horne, visto que en ellas la intuición de una totalidad orgánica se sostiene pura y exclusivamente sobre la contundencia estética de la obra singular desprendida de su contexto. Sin embargo, es en Scrovegni donde se aprecia con mayor fuerza el efecto. Esta dialéctica entre unidades y totalidades de sentido que señala Imdahl es, sin duda y en gran parte, responsable del efecto de la evidencia. Pero es también una instancia secundaria de la apreciación estética, una instancia mediada por un momento anterior de recogimiento reflexivo que se nutre de la percepción inicial. En la percepción inicial ya hay evidencia y ésta es producto de una ilusión, la ilusión de lo atemporal.

Mientras que los críticos de Giotto han destacado una y otra vez con justa razón la creación de espacialidad como una de las notas más sobresalientes del genio del artista (el Giotto spazioso, en palabras de Longhi), en particular en relación con los frescos de Scrovegni, pocos han prestado atención a la ilusión temporal, o más bien atemporal, que generan en el visitante

21 Imdahl, Arenafresken: Ikonographie, Ikonologie, Ikonik, 59. esta espacialidad omniabarcante y esos colores entre telúricos y oníricos. La aprehensión de evidencia es un efecto cuasi epifánico del entrecruzamiento de dos ejes: el espacio totalizante y la atemporalidad. Las figuras que viven en los muros de Scrovegni son presencias puramente espaciales que no conocen el tiempo pues en Giotto no hay tiempo, solo hay instante. El espacio se despliega de una vez y para siempre en un eterno presente. Y la acción dramática es una instantánea de tensión suspendida que no tiene comienzo ni fin. La clave de esta atemporalidad radical, que es la clave de la potencia del estilo giottesco, está en los ojos de los personajes y en sus miradas que sutilmente referencian una temporalidad que nunca se concreta. Los ojos de Giotto son ventanas a algo que acaba de pasar o que está a punto de pasar, pero nunca a lo que está pasando, a la escena misma. El ejemplo más famoso es "El beso de Judas". Giotto se centra en el instante inmediatamente posterior al beso, cuando San Pedro ya está cortándole la oreja a Malco. El rostro de Judas muestra un atisbo, no de arrepentimiento, pero sí de conciencia de la magnitud de lo que acaba de hacer. En esta disonancia visual y narrativa se ubica el punto de fuga de los ejes del espacio total y del tiempo fosilizado o, mejor dicho, cancelado.

Tomemos un ejemplo de la primera serie de historias en la franja superior del muro a la izquierda del altar. Se trata de escenas de la vida de Joaquín y Ana, los padres de la Virgen. En particular, centremos la atención en el "Encuentro ante la Puerta Dorada", un episodio tomado del Evangelio del Pseudo-Mateo (3.5). Luego de cuarenta días de soledad en el desierto, durante los cuales Joaquín hace penitencia para ser digno de recibir la gracia de Dios y ser capaz de procrear, el padre de la Virgen se encuentra con su mujer en las puertas de Jerusalén. Joaquín no lo sabe, pero Ana ha recibido la visita de un ángel que le anunció que será madre. Los esposos se encuentran y se besan. Él la abraza, ella lo toma de la nuca con una mano y con la otra le acaricia la barba. La escena es tierna y conmovedora, 


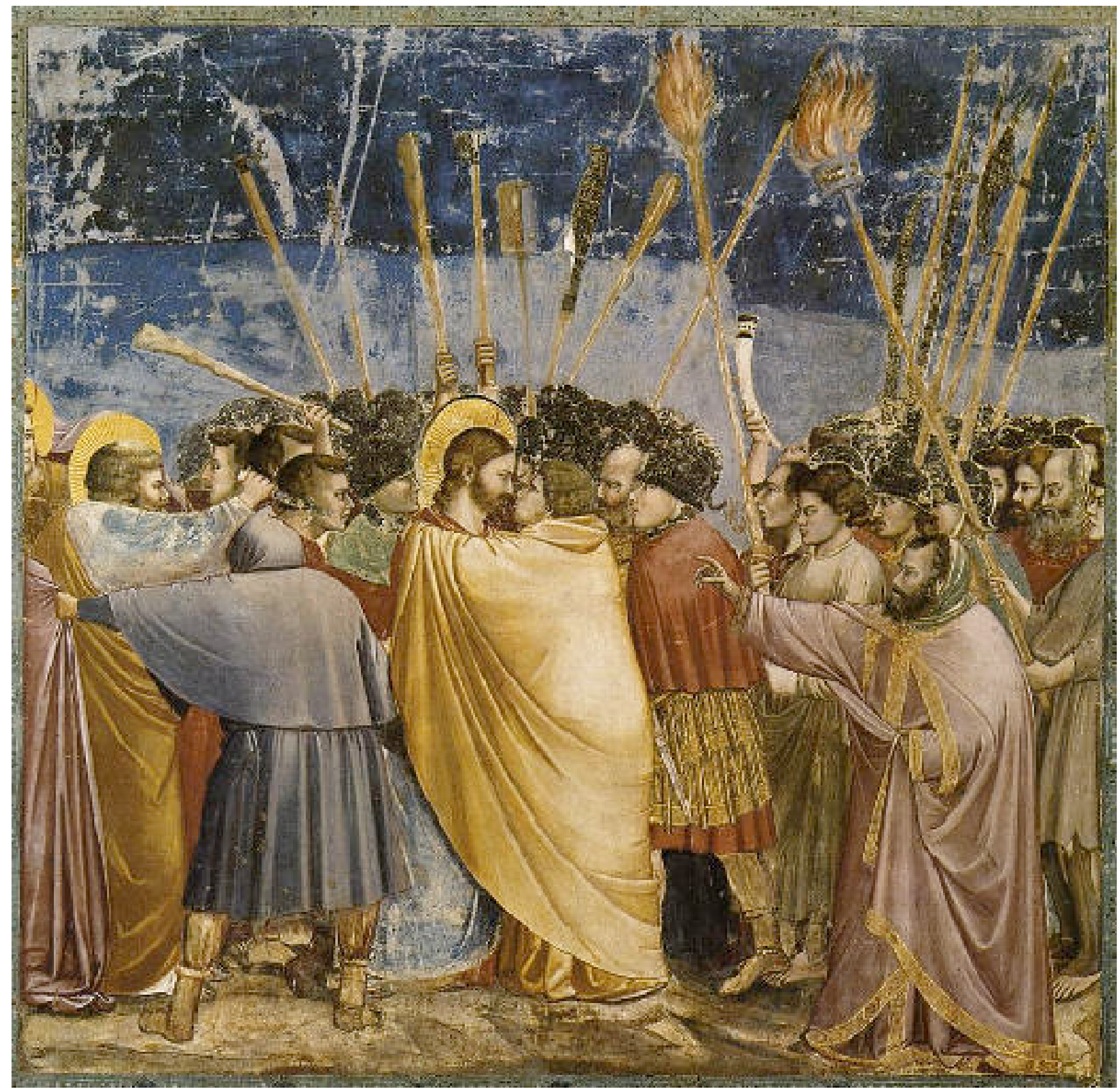

El beso de Judas representado por Giotto en la Capilla de los Scrovegni, Padua, Italia, circa 1304. Fuente: Wikimedia Commons.

ambos tienen los ojos abiertos pero sus miradas no se alinean. La pupila del ojo derecho de Joaquín está en línea recta con la oreja de Ana y el abuelo de Cristo pareciera estar mirando hacia la Puerta Dorada, bajo cuyo arco hay cuatro mujeres que observan el reencuentro. La mirada de Ana, en cambio, sí se dirige hacia su marido. El ojo izquierdo, abierto y atento, se clava en la totalidad de Joaquín. Hay, sin embargo, una nota irreal en su mirada demasiado concentrada y demasiado fija en un punto indeterminado del cuerpo de su marido. Estos dos ojos armoniosamente desalineados evocan una dimensión de ensueño, a la vez arcaica y supraterrenal, que da a la escena toda una poderosa sensación de atemporalidad. 
Pero este cruce de miradas desfasadas no es más que el epicentro de un complicado juego de ojos. Bajo el arco de la Puerta Dorada hay cuatro mujeres que miran a los futuros padres. Al menos, esa es la impresión que dan a simple vista. Sus miradas se dirigen hacia la pareja, aunque si trazamos una línea desde cada una de sus pupilas comprobamos que ninguna de ellas está mirando a Joaquín y a Ana. No está claro qué miran, pero es algo que está más allá de los cónyuges. ¿El pastor que secunda a Joaquín? ¿Algo o alguien que está fuera de la escena? ¿Acaso el desierto, de donde viene Joaquín? Por su parte, el pastor que sigue a Joaquín mira hacia la Puerta Dorada, pero es imposible determinar si posa su mirada sobre alguien o algo en particular. Tenemos entonces dos grupos de miradas que van en direcciones contrarias sin cruzarse. De un lado, Ana y las cuatro mujeres, que miran hacia afuera. Del otro, Joaquín y el pastor que miran hacia adentro. Pero hay un octavo personaje que trastorna la escena al tiempo que la organiza: la dama de negro.

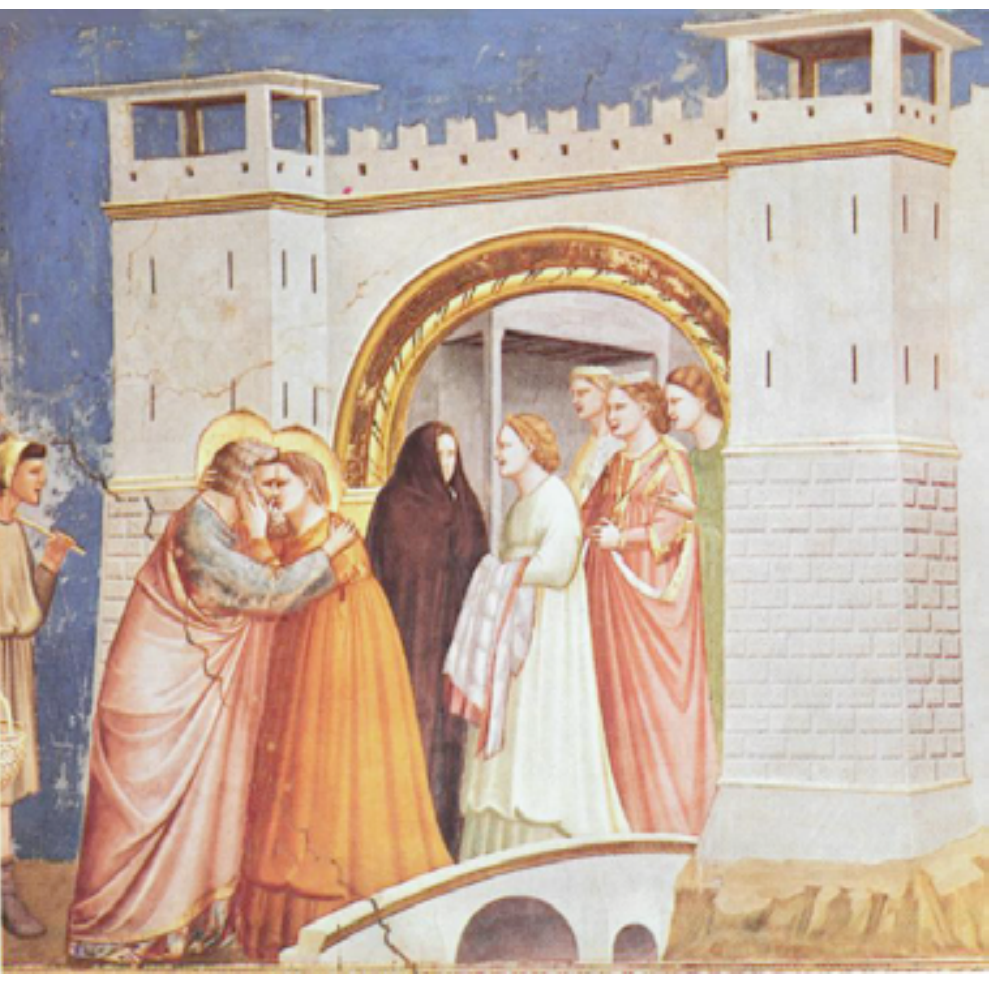

Joaquín y Ana se encuentran ante la Puerta Dorada, fresco de Giotto, circa 1305. Fuente: Wikimedia Commons.
La pareja de ancianos es el foco de la historia y sin embargo Giotto no los ubica en el centro de la escena sino ligeramente hacia la izquierda. El centro lo ocupa la dama de negro, que está de espaldas a Joaquín y Ana con la mirada dirigida hacia el grupo de mujeres, o tal vez hacia el interior de la ciudad. El significado de este personaje no es claro y ha dado de qué hablar a los críticos. Su presencia taciturna y opaca genera un pronunciado contraste con la dicha general de la escena del reencuentro y con la noticia milagrosa de la inminente concepción. Su posición y la dirección de su mirada es un misterio. ¿Por qué ignora a los futuros padres? ¿Es acaso un personaje premonitorio, un recordatorio del sufrimiento que le espera a esa niña tan anhelada por la pareja, una anticipación ominosa de episodios cruentos como la masacre de los inocentes y del calvario? ¿Representa quizá a la Sinagoga, que le dará la espalda a la buena nueva ${ }^{22} \mathrm{O}$, tal vez, el objeto de su mirada esté más allá.

"El encuentro ante la Puerta Dorada" es la última escena de la franja superior del muro izquierdo si uno se ubica en el altar. La escena que le sigue cronológicamente -el nacimiento de la Virgen- está en la

22 Smart sugiere que la misteriosa dama de negro podría representar a la Sinagoga, que en el imaginario medieval era una anciana vestida de negro y velada o con los ojos vendados. Su posición, de espaldas a la escena del reencuentro, anticiparía la reticencia de los judíos frente a Jesús como el mesías. Ver Alastair Smart, The Assisi Problem and the Art of Giotto: A Study of the Legend of St. Francis in the Upper Church of San Francesco, 105. Chiara Frugoni, en cambio, menciona también como posible fuente de inspiración una famosa figura de Medea esculpida en un sarcófago romano que se ha perdido, pero del que se conserva un dibujo renacentista que muestra a la famosa matricida envuelta en un manto de manera muy similar a la dama de negro. Esta referencia establecería una conexión entre "El encuentro ante la Puerta Dorada" y "La matanza de los inocentes". Ver Frugoni, L'affare migliore di Enrico. Giotto e la cappella Scrovegni, 126. 
pared opuesta, siempre en la franja superior y directamente enfrente. Pero para llegar ahí con la mirada hay que pasar por el muro opuesto al altar, donde se encuentra la entrada a la capilla y donde Giotto dispuso el Juicio Final. ¿Es ahí donde nos dirige la dama de negro? ¿Hacia el Cristo entronado que juzga, premia y castiga? La mirada de la dama no es siniestra, sino más bien preclara, como si su rol fuese el de recordarle al espectador el sentido escatológico de la historia y advertirle que no se pierda en la cálida emoción que suscita la escena. El nacimiento de la Virgen conduce a la encarnación que a su vez conduce a la pasión, la resurrección, el Juicio Final y el fin de los tiempos. Si los ojos de la dama de negro indican efectivamente el final de los tiempos, entonces no son más que una representación explícita de la resistencia a la dimensión temporal que también expresan los ojos de Joaquín y de Ana, los de las mujeres bajo el arco de la puerta, los del pastor y los de tantos otros personajes en los muros de Scrovegni. Esos ojos almendrados, marca registrada del estilo giottesco, funcionan como ventanas a una dimensión arcaica e irreal que remite al fin de la historia o al mundo de los sueños, que también está afuera del tiempo. El color verdaccio, una combinación de marrón y verde, a veces grisáceo, a veces amarillento, se lograba mezclando pigmentos blancos, negros y amarillos y era usado comúnmente para los rostros en la pintura al fresco. Este color da a los ojos de Giotto un tono ligeramente inquietante, inhumano (reptiliano incluso), que contribuye al efecto de atemporalidad.

Los discípulos directos e indirectos de Giotto (Taddeo y Agnolo Gaddi, Stefano Fiorentino y su hijo, el Giottino, Andrea Pisano y otros) comprendieron la importancia de esos ojos de almendra, nunca del todo abiertos, pero siempre visionarios, que no se sabe bien hacia dónde miran y mediante los cuales el maestro expresa la emoción con ese vigor "naturalista" y franciscano que impactó tanto en sus primeros críticos. La concisión narrativa de Giotto, que logra en cada recuadro síntesis compactas de dramatismo y evidencia, se resume en esos ojos que oscilan entre lo inhumano y lo sobrehumano y en esas miradas desfasadas que dirigen la atención de quien observa hacia referentes inciertos. Así, el espectador, como el lector al que se dirige Dante, completa la escena con su dosis de fe, con su suspensión involuntaria de la incredulidad, mientras busca el objeto de las miradas. La búsqueda es en vano porque el punto de fuga de todas las miradas es la eternidad.

Sin ánimo de forzar la conexión entre Giotto y Dante (sí, posiblemente se hayan conocido; sí, Giotto es el único artista contemporáneo mencionado en $\mathrm{La} \mathrm{Di}$ vina Comedia; sí, el estilo de ambos se caracteriza por una proverbial economía narrativa y por una habilidad descollante para generar verosimilitud afectiva), vuelvo al final del canto décimo sexto del Infierno y a la imagen de la verdad con cara de mentira que sintetiza la naturaleza de la poesía profética y que funciona como antídoto contra el fraude. Hay dos detalles en la Capilla de los Scrovegni, dos rincones pintados a la manera de pequeñas ventanas que producen la ilusión tridimensional de un espacio contiguo vacío, un coretto. Son detalles que refuerzan la imagen de Giotto como maestro ilusionista, precursor de la perspectiva lineal y anti-naturalista. ${ }^{23}$ Estos vanos funcionan como trucos para el ojo, son mentiras con cara de verdad. Pero tal vez en el universo cerrado, autocontenido y atemporal de Scrovegni sean verdades con cara de mentira. Al igual que la advertencia de Dante

23 Longhi, Gombrich, Cole y otros resaltaron la capacidad ilusionística de Giotto. Cole dice que el pintor es "heredero de un arte que se transformaba lentamente de la abstracción al ilusionismo" (Cole, Giotto and Florentine Painting 1280-1375, 39). Pero Vasari (Le vite de'più eccellenti pittori, scultori e architettori, 110) ya había elogiado la habilidad de Giotto para el escorzo. Ver:Gombrich, The Story of Art, 151. Longhi, "Giotto Spazioso" en "Giudizio sul Duecento" e ricerche sul Trecento nell'Italia centrale, 62. 
al lector, cuando el poeta afirma con vehemencia su credibilidad justo antes de describir como verdadera una quimera de su imaginación abismal, los trucos de Giotto ilusionista, así como las miradas desalineadas y disruptivas de sus personajes, lejos de ser tretas para engañar al espectador, acaso sean modos de construir evidencia y de establecer las condiciones necesarias para que se produzca el efecto último y fundamental al que aspiraba el arte en el medioevo: facilitar la epifanía de trascendencia.

\section{Referencias}

Alighieri, Dante. Commedia, Vol. I, Inferno, comentario Anna Maria Chiavacci Leonardi. Milán: Mondadori, 1991.

_. La divina comedia, ed. Ángel Chiclana. Barcelona: Austral, 2010. Kindle.

Auerbach Erich. Il fattore personale nell'ascendente di San Francesco d'Assisi, in Id., San Francesco, Dante, Vico e altri saggi di filologia romanza, trad. it. V. Ruberl. Roma: Editori Riuniti, 1987.

_. "Dante's Addresses to the Reader." Romance Philology 7, no. 4 (May 1954): 268-278.

Battisti, Eugenio. "Giotto nel Trecento." In Rinascimento e Barocco. Torino: Einaudi, 1960.

Belting, Hans. "The New Role of Narrative in Public Painting of the Trecento: 'Historia' and Allegory." In Studies in the History of Art Vol. 16, Symposium Papers IV: Pictorial Narrative in Antiquity and the Middle Ages (1985). http://www.jstor.org/stable/42617840 Revisado el 9 de septiembre, 2021.

Benedictis, Cristina de. Giotto: Bibliografía Vol. II (1937-1970). Roma: Ist. Arch. e storia dell'Arte, 1973. Boccaccio, Giovanni. El Decamerón, trad. Luis Obiols. Buenos Aires: Ateneo, 1953.

Brinckmann, Albert E. "Dante und die blindende Kunst." Kunstchronik und Kunstmarkt, no. 50-51 (Septiembre 1921). https://doi.org/10.11588/diglit.36987.71 Revisado el 9 de septiembre, 2021.

Caretti, Lafranco. "Storia e poesía (Inferno XVI)." In Antichi e moderni: studi di letteratura italiana. Torino: Einaudi, 1976.

Cennini, Cennino. Il libro dell'arte: A new English translation and Commentary with Italian Transcription, trad. Lara Broecke. Londres: Archetype Publications, 2015.

Cole, Bruce. Giotto and Florentine Painting 1280-1375. New York: Harper \& Row, 1976.
Da Pisa, Guido. Expositiones et Glose super Comediam Dantis, ed. Vincenzo Cioffari Albania: State University of New York Press, 1974.

Frugoni, Chiara. L'affare migliore di Enrico. Giotto e la cappella Scrovegni. Torino: Einaudi, 2008.

Ghiberti, Lorenzo. I comentario (Biblioteca Nazionale Centrale di Firenze, II, i, 333), ed. Lorenzo Bartoli. Florencia: Giunti, 1998.

Gizzi, Corrado. Giotto e Dante. Milán: Skira, 2001. Gombrich, E. H. The Story of Art. Austria: Phaidon, 2011. Imdahl, Max. Giotto Arenafresken: Ikonographie, Ikonologie, Ikonik. Munich: Wilhelm Fink Verlag, 1980.

Longhi, Roberto. "Giotto Spazioso." In "Giudizio sul Duecento" e ricerche sul Trecento nell'Italia centrale. Florencia: Sanzoni Editore, 1974.

Offner, Richard. "Giotto, Non-Giotto-II." The Burlington Magazine for Connoisseurs 75, no. 438 (Sep,1939). http://www.jstor.org/stable/867891 Revisado el 9 de septiembre de 2021.

. "Giotto, Non-Giotto." The Burlington Magazine for Connoisseurs 74, no. 435 (Jun,1939). https://www.jstor. org/stable/867802 Revisado el 9 de septiembre de 2021.

Proust, Marcel. En busca del tiempo perdido 6. La fugitiva, trad. Consuelo Berges. Madrid: Alianza, 2001.

Ruskin, John. Giotto And His Works In Padua: Being An Explanatory Notice of the Series of Woodcuts Executed for the Arundel Society After the Frescoes in the Arena Chapel. Londres: The Arundel Society, 1854.

Salvini, Roberto. Giotto: La cappella degli Scrovegni. Florencia: Arnaud 1956.

Smart, Alastair. The Assisi Problem and the Art of Giotto: A Study of the Legend of St. Francis in the Upper Church of San Francesco, Assisi. Oxford: Clarendon Press, 1971.

Thode, Henry. Giotto, KünstlerMonographien 43, ed. W.F. Volbach. Bielefeld: Velhagen \& Klasing, 1926.

Vasari, Giorgio. Le vite de'più eccellenti pittori, scultori e architettori, Vol. I, ed. Paola Della Pertola, Luigi Grassi y Giovanni Previtali. Milán: Il Club del Libro,1962-66.

Villani, Filippo y Giammaria Mazzuchelli. Le vite d'uomini illustri fiorentini. Florencia: Sansone Coen TipografoEditore, 1847. 